\title{
Depression, Anxiety and Cardiac Surgery in the Indian scenario: a review
}

\author{
Mridula C. Jobson ${ }^{1}$, A.J. Rajendran ${ }^{2}$ \\ ${ }^{1}$ Psychologist, \\ ${ }^{2}$ Senior Consultant and Lead, \\ Department of Rehabilitation Medicine, MGM Healthcare Pvt. Ltd., Chennai. \\ Corresponding author: Mridula Jobson \\ Email - mridulacjobson@gmail.com
}

\begin{abstract}
Up to 15 percent of patients with cardiovascular disease and up to 20 percent of patients who have undergone coronary artery bypass graft (CABG) surgery experience major depression. For more than two decades, the prognostic influence of depression on cardiac surgery is unavoidable. Cardiac surgery may provide a suitable exemplar to better understanding of psychological mechanism of cardio-pathogenesis. It is surprise considering that some pathophysiological mechanisms through which depression is hypothesized to affect coronary heart disease exhibit a paucity of research till date.Addressing the depressed patient has traditionally not been a priority in the management of cardiac surgical patients despite the fact that a disproportionate number of patients in the cardiac surgery population suffer from depression. Naturally, the rates of depression after cardiac surgery highlight a requirement for appropriate identification, support, and intervention efforts. Collaboration between psychologists and psychiatrist specialists with cardiac surgeons, cardiologists, and cardiac nurses may enhance the research basis for improved patient outcomes. It is commonly hoped that intervention might mitigate the deleterious impact of depression on subsequent morbidity and mortality.
\end{abstract}

Key words: depression, anxiety, cardiac surgery, cardiology, behavioural cardiology.

(Paper received $-9^{\text {th }}$ May 2020, Peer review completed $-16^{\text {th }}$ June 2020)

(Accepted $-18^{\text {th }}$ June 2020)

\section{INTRODUCTION}

The mind-body link has always fascinated medical man as ultimate acknowledgment of good treatment will eventually be appreciated by the mind and not the body. Major depression is predictive of developing cardiac disease and of adverse outcomes among patients with existing cardiac disease and surgery [1-4]. The current paper explores the mutual impact of major depression and cardiac surgery have on each other. It is common for a cardiac patient to feel sad after cardiac surgery or procedure, recent hospitalization, or new diagnosis of heart disease. These emotions may be the result of not knowing what to expect or not being able to do simple tasks. These temporary feelings of sadness are normal, and should gradually go away, when such common sadness, fear and hopelessness persist and transforms into anxiety, depression creates a bizarre situation and events to follow. When depressed mood is severe and accompanied by other symptoms that persist every day pre-operatively and post-operatively and continues even after discharge for 2 or more weeks, treatment becomes mandatory to cope and recover.

Coronary artery bypass graft (CABG) surgery leads to a $25 \%$ incidence of major depression and up to a $75 \%$ incidence of adjustment disorder with depressed mood. Screening patients for depression during the preoperative work-up may reap benefits for the patient with regard to the smoothness of the postoperative recovery [5-8]. The scientific field of cardiac psychology, also known as behavioral cardiology and 
psychocardiology, began long back on 1959 when Friedman and Rosenman, two cardiologists, invented the 'type A behavior pattern (TABP)', the two major symptoms of which are easily aroused anger (free floating hostility) and time pressure (doing too much in too little time). World Health Organization (WHO) describes health as a state of complete physical, mental, and social well-being and not merely an absence of disease or infirmity. Conceptually Cardiac psychology or Behavioral Cardiology is a newly emerging concept high-lighting the need for psychology intervention in patients suffering from cardiac diseases [811]. Although the psychological side effects of cardiac surgery have long been of interest, the prevalence and influence of depression and anxiety on patients undergoing cardiac surgery lag behind the evidence documented in heart failure, myocardial infarction, and acute coronary syndromes. Rather, in cardiac surgery, an emphasis has been placed on preserving cognitive function but not mental health function [1114].

A PubMed search of the terms "psychosocial factors and cardiovascular disease" now yields more than 52,000 citations. Research links depression, social isolation, anxiety, anger, as well as a number of less researched psychosocial factors, with both the onset and poor treatment outcome of coronary heart disease (CHD). A meta-analysis of 893,500 initially healthy subjects reported that depression is a risk factor for both MI and CHD [15], while another meta-analysis with 317,540 subjects determined that depression is a risk factor for non-fatal and fatal stroke [16]. In 2014, an expert panel convened by the American Heart Association recommended that depression be elevated to risk factor status for patients with acute coronary syndrome (ACS) [17]. Anxiety has been associated with increased risk of cardiovascular mortality of CHD, stroke, and heart failure in a meta-analysis with 2,017,276 subjects [17]

\section{CABG: INDIAN SCENARIO}

High levels of evidence suggest significant benefits with respect to morbidity and mortality in addition to cost savings. However, behavior cardiology is grossly underutilized and has not received the attention it deserves in India [18-19]. This underutilization is due to the various barriers that exist with respect to awareness and understanding of the benefits health-care professionals, referrals, limited presence of specialized professionals, and a lack of awareness among patients on the benefits of behavior modifications and mind wellness. Majority of patients remain undiagnosed and those who are diagnosed have limited means of specialized care. But booming of medical tourism have paved a path for many tertiary care superspecialty hospitals cater to complete healthcare who exclusively visit India for medical reasons [20]. This has now changed the scenario for Indian patients as well. Many such hospitals offer medical package for a particular amount and the macro- and microeconomics determine the kind of medical care that will eventually be rendered to the patients [21]. Another finding is that majority of Indian patients also have many modifiable risk factors like high stress levels, smoking, hypertension, obesity, and diabetes [21-22] and non -modifiable risk factors such as age and gender. Such information opens a window of opportunity for collaborative intervention for long-term gains.

\section{CABG AND PSYCHOPATHOLOGY}

The range of complications ranges vary depend upon the vascular involvement. The deep involvement of Psychological, sociological and environmental factors which act as influencers of anxiety, depression, neurocognitive deficits, delirium, and cerebrovascular accident becomes inevitable [23]. For more than 15 years, WHO has been sounding an alarm on the rapidly rising burden of cardiovascular disorders. The incidence and prevalence in Indian population may be higher because of sociodemographic reasons [24]. During the early stages, management of CAD includes dietary and life style modification, lipid lowering agents, blood pressure monitoring, glycemic control, and antiplatelet agents. As the disease progresses, these measures are not sufficient to maintain a satisfactory quality of life. Over the years, refinement of surgical and anesthetic procedures has led to significant reduction in mortality and morbidity [10]. However, still a significant number of patients do have associated psychological morbidity which is disabling and distressing. Relationship of psychological symptoms with coronary heart disease has been well known since a long time [11]. It is important to note that psychological illness when co-morbid with 
cardiac illness generally leads to poorer outcomes [20-25]. Depression has been found to be an independent prognostic factor for mortality, readmission, cardiac events, and lack of functional benefits 6 months to 5 years after CABG [13-16]. These observations highlight the need for integrating psychosocial interventions to provide holistic and effective management after CABG. Studies using self-report depression measures suggest up to $50 \%$ of patients experience depressive symptoms [9, 11-13]. Studies using self-report measures do not reflect a clinical diagnosis of depression but, rather, depression symptoms.

\section{CONCEPT OF DEPRESSION AND ANXIETY}

According to the International Classification for Diseases tenth edition (ICD-10), depression is characterized by low mood and/or anhedonia (loss of interest in activities that once were pleasurable) that lasts for two weeks or more and is accompanied by significant functional impairment and somatic complaints of disturbed sleep, fatigue, body aches, digestive or sexual problems, and negative thoughts. Depression and coronary artery disease are highly comorbid conditions with estimates of comorbidity from $14 \%$ to $47 \%$ [26-27]. Though both depression and CAD may share same etiopathogenesis, they both need to be diagnosed and treated independently [28]. It is like a patient suffering abdominal trauma and fractured femur following an accident. Both conditions need attention for complete recovery. Preoperative depression is predictive of decreased cardiac symptom relief, quicker return of symptoms, more frequent rehospitalizations, and increased mortality in the immediate postoperative period [29]. Postoperative depression too is associated with delayed wound healing, higher infection rate, poor physical and emotional health, reduced pain threshold, and more adverse cardiac events like myocardial infarction and early death [30-32]. All these factors lead to poor overall quality of life and rising health costs. Depression is considered to be a risk factor for the development of $\mathrm{CHD}$ and deteriorates the outcome after cardiac rehabilitation efforts [33-36].

Anxiety on the other hand refers to feeling of apprehension and unease. Anxiety has somatic, physiological, and cognitive components. Somatic component refers to digital tremors, palpitations, and sweaty palms. The physiological component refers to tachycardia, hyperventilation, muscular tension, and an irritable bladder. The cognitive component is that of worry which refers to undue fear of something untoward happening [18]. Pathological anxiety manifests as a feeling of impending doom, excessive worrying thoughts of being disabled, persistent palpitations, generalized muscular tension with inability to relax, breathlessness, hyper vigilance, persistent headache, frequent urge to pass urine, butterflies in stomach, and persistent sleep disturbance. Frequently, such symptoms are either ignored or not asked/reported. However, they cause significant distress and may lead to adverse outcomes. It has been found to be unusually high for CABG patients while on the waiting list with an unknown surgery date [30]. Fear of dying before rather than during surgery has been highlighted as a pervasive and anxious preoccupation [18]. Following CABG, anxiety precipitates cardiac decompensation owing to higher autonomic arousal thus delaying healing and recovery. The most common anxiety disorders appear to be generalized anxiety disorder (GAD) and panic Disorder with prevalence ranging from $0-11 \%$. Other anxiety disorders are phobias (2.5-4.3\%), obsessive compulsive disorder (0.6-9\%) and posttraumatic stress disorder (PTSD) (4-11\%) [18].

It is not uncommon to find both depression and anxiety to coexist on a continuum so much so that they are considered together as both impair one's quality of life and interfere significantly with the ability to think rationally. Researchers have tried to pinpoint the etiological basis of depression in cardiac illnesses and have implicated factors like hypercortisolemia, insulin resistance and sympathetic- parasympathetic tone dysregulation, reduced heart rate variability, hypothalamic-pituitary-adrenal axis (HPA) axis, and increased inflammatory factors like platelet factor 4, fibrinogen, and C-reactive protein. Unhealthy lifestyle like cigarette smoking, excessive alcohol intake, lack of physical exercise, poor medications adherence, and unhealthy diet may also be directly or indirectly contributing to the onset and progression of depression [20-22]. Recent publications have indicated that routine screening of depression should be introduced as standard practice in the preoperative assessment of patients undergoing cardiac procedures [3, 5-7]. 


\section{MULTI SUPER-SPECIALTY INTERFACE: CARDIOLOGY, NEUROLOGY \& PSYCHIATRY}

The interface between heart and the mind is too strong to be neglected. For reasoning to exist, a fine balance between the mind and the heart is needed for rational decision- making. When we speak of the mind, we refer to the software of the hardware that we call brain. The reliability and the functionality of this software (mind) are based on prime functioning of the underlying hardware (brain). Any insult to the structural integrity of the brain often gets translated into cognitive, emotional, motor, or sensory symptoms [17]. The purpose of this review study is to highlight the role of early identification and management of emotional disorders that are encountered while caring for the patients undergoing CABG.

\section{MANIFESTATIONS OF DEPRESSION AND ANXIETY IN INDIAN SUBJECTS}

Fatigue, loss of appetite, psychomotor retardation, insomnia, and difficulty concentrating can be the direct physiological response to a medical illness and hospitalization [20] and have been documented to significantly increase in the first month after CABG surgery [21]. Important risk factors associated with a major depression episode among patients undergoing $C A B G$ surgery include female gender, younger age, a previous depression episode, and evidence of a family history of depression [8]. Patients at high risk might warrant closer monitoring during the perioperative period with respect to depression and related psychiatric sequel such as delirium, as described subsequently.

\section{CONCLUSION AND FUTURE RESEARCH DIRECTIONS}

The interaction between depression pathophysiology and effects of cardiopulmonary bypass is a potentially fruitful avenue of research in cardiac surgery to better understand mechanisms of psychiatric cardio-pathogenesis. Coronary artery disease is the most important cause of morbidity and mortality in Indian subcontinent. There have been rapid advances in the care of those suffering its effects. Strong biological link between emotional state and coronary artery disease is well established. It may be prudent to screen the patients during routine workup before and after surgery. Many patients may not be able to describe their symptoms in busy outpatient set-up. Under such conditions, patient education and awareness may be a useful strategy. Collaboration between psychologists and psychiatrist specialists with cardiac surgeons, cardiologists, and cardiac nurses may enhance the research basis for improved patient outcomes. Depression is prevalent in approximately one-third of patients undergoing cardiac surgery at the time of discharge. Preoperatively depressed patients tend to have an improvement in depression scores, whereas other patients have worsening of depressive symptoms. Future studies are necessary to develop effective, timely treatment strategies for the different subgroups of depressed patients before and after cardiac surgery

\section{REFERENCES}

1. Fox H, Rizzon N, Gifford S.Psychological observations of patients undergoing mitral surgery: A study of stress. Am Heart J 1954;48:645-70.

2. Gilman S. Cerebral disorders after open-heart operations. N Engl J Med 1965;272:489-98.

3. Tully PJ, Baker RA.Depression and anxiety and morbidity outcomes after coronary artery bypass graft surgery patients: A practical and contemporary review. J Geriatr Cardiol 2012;9:197-208.

4. Connerney I, Shapiro PA, McLaughlin JS, Bagiella E, Sloan RP.Relation between depression after coronary artery bypass surgery and 12-month outcome: A prospective study. Lancet 2001;358:1766-71

5. Tully PJ, Baker RA, Winefield HR, Turnbull DA. Depression, anxiety disorders and Type D personality as risk factors for delirium after cardiac surgery. Austr N Z J Psychiatry 2010;44:1005-11.

6. Fraguas R Junior, Ramadan ZB, Pereira AN, Wajngarten M. Depression with irritability in patients undergoing coronary artery bypass graft surgery: The cardiologist's role. Gen Hosp Psychiatry 2000;22:36574.

7. Tully P. Psychological depression and cardiac surgery: A comprehensive review. J Extra Corpor Technol 2012;44:224-32.

8. Rumsfeld JS, Ho PM. Depression and cardiovascular disease: A call for recognition. Circulation 2005;111:250-3. 
9. Mallik S, Krumholz HM, Lin ZQ, Kasl SV, Mattera JA, Roumains SA, Vaccarino V. Patients with depressive symptoms have lower health status benefits after coronary artery bypass surgery. Circulation 2005;111(3):271-7.

10. Lozano R, Naghavi M, Foreman K, AlMazroa MA, Memish ZA. Global and regional mortality from 235 causes of death for 20 age groups in 1990 and 2010: a systematic analysis for the Global Burden of Disease Study 2010 (vol 380, pg 2095, 2012). Lancet 2013;381(9867):628-.

11. Osterberg L, Blaschke T. Adherence to medication. N Engl J Med 2005;353(5):487-97.

12. Bosworth HB, Granger BB, Mendys P, Brindis R, Burkholder R, Czajkowski SM, Daniel JG, Ekman I, Ho M, Johnson M, Kimmel SE. Medication adherence: a call for action. Am Heart J 2011;162(3):412-24.

13. Perk J, De Backer G, Gohlke H, Graham I, Reiner Ž, Verschuren M, Albus C, Benlian P, Boysen G, Cifkova R. European Guidelines on cardiovascular disease prevention in clinical practice (version 2012) The Fifth Joint Task Force of the European Society of Cardiology and Other Societies on Cardiovascular Disease Prevention in Clinical Practice (constituted by representatives of nine societies and by invited experts) Developed with the special contribution of the European Association for Cardiovascular Prevention \& Rehabilitation (EACPR). Eur Heart J 2012;33(13):1635-701.

14. Oliveira AD, Filho, Morisky DE, Costa FA, Pacheco ST, Neves SF, Lyra-Jr DP. Otimização da adesão terapêutica pós-alta hospitalar de pacientes com DCV: ensaio clínico randomizado - estudo piloto. Arq Bras Cardiol 2014;103(5):502-12.

15. Fraguas Jr R, Ramadan ZB, Pereira AN, Wajngarten M. Depression with irritability in patients undergoing coronary arterybypass graft surgery: The cardiologist's role. Gen Hosp Psychiatry 2000;22(4):365-74.

16. Rafanelli C, Roncuzzi R, Milaneschi Y. Minor depression as a cardiac risk factor after coronary artery bypass surgery. Psychosomatics 2006; 47(3):289-95.

17. Mitchell RH, Robertson E, Harvey PJ, Nolan R, Rodin G, Romans S, Abramson BL, Brister SJ, Ivanov J, Stewart DE. Sex differences in depression after coronary artery bypass graft surgery. Am Heart J 2005;150(5):1017-25.

18. Hedge J, Balajibabu P R, Sivaraman T. The patient with ischaemic heart disease undergoing non cardiac surgery. Indian J Anaesth 2017;61:705-11.

19. Hall MJ, Owings MF, Hyattsville MD. Department of Health and Human Services 2002. Advance Data From Vital and Health Statistics, No. 329. National Hospital Discharge Survey (PHS) June 19, 2002

20. Kaul TK, Tayal G. Anaesthetic considerations in cardiac patients undergoing non cardiac surgery. Indian J Anaesth 2007;51:280-6.

21. Dao TK, Youssef NA, Armsworth M, Wear E, Papathopoulos KN, Gopaldas R. Randomized controlled trial of brief cognitive behavioralintervention for depression and anxiety symptoms preoperatively inpatients undergoing coronary artery bypass graft surgery. J Thorac Cardiovasc Surg 2011;142:e109-15.

22. Rollman BL, Belnap BH, LeMenager MS, Mazumdar S, Houck PR, Counihan PJ, Kapoor WN, Schulberg $\mathrm{HC}$, Reynolds CF. Telephone-delivered collaborative care for treating post-CABG depression: a randomized controlled trial. JAMA 2009;302(19):2095-103.

23. Shemesh E, Annunziato RA, Rubinstein D, Sultan S, Malhotra J, Santra M, Weatherley BD, Feaganes JR, Cotter G, Yehuda R. Screening for depression and suicidality in patients with cardiovascular illnesses. The Am j Cardiol 2009;104(9):1194-7.

24. Koenig HG, George LK, Peterson BL, Pieper CF. Depression inmedically ill hospitalized older adults: Prevalence, characteristics, and course of symptoms according to six diagnostic schemes. Am J Psychiatry 1997; 154:1376-83.

25. Contrada RJ, Boulifard DA, Idler EL, Krause TJ, Labouvie EW. Course of depressive symptoms in patients undergoing heart surgery: Confirmatory analysis of the factor pattern and latent mean structure of the Center for Epidemiologic Studies Depression Scale. Psychosom Med. 2006;68:922-30.

26. Baker RA, Andrew MJ, Schrader G, Knight JL. Preoperative depression and mortality in coronary artery bypass surgery: preliminary findings. Aust N Z J Surg 2001;71:139-42.

27. American Psychiatric Association. Diagnostic and Statistical Manualof Mental Disorders: DSM-IV-TR. Washington, DC: American Psychiatric Association; 2000.

28. Tully PJ, Baker RA, Turnbull D, Winefield $\mathrm{H}$. The role of depression and anxiety symptoms and hospital readmissions after cardiac surgery. J Behav Med. 2008;31:281-90.

29. Borowicz L Jr, Royall R, Grega M, Selnes O, Lyketsos C, McKhann G. Depression and cardiac morbidity 5 years after coronary artery bypass surgery. Psychosomatics 2002;43:464-71.

30. McKhann GM, Borowicz LM, Goldsborough MA, Enger C, Selnes OA. Depression and cognitive decline after coronary artery bypass grafting. Lancet 1997;349:1282-4

31. Peterson JC, Charlson ME, Williams-Russo P, Krieger KH, Pirraglia PA, Meyers BS, Alexopoulos GS. New postoperative depressive symptoms and long-term cardiac outcomes after coronary artery bypass surgery. Am J Geriatr Psychiatry 2002;10(2):192-8.

32. Smith Jr SC, Benjamin EJ, Bonow RO, Braun LT, Creager MA, Franklin BA, Gibbons RJ, Grundy SM, Hiratzka LF, Jones DW, Lloyd-Jones DM. AHA/ACCF secondary prevention and risk reduction therapy for patients with coronary and other atherosclerotic vascular disease: 2011 update: a guideline from the American Heart Association and American College of Cardiology Foundation. Circulation 2011;124(22):2458-73.

33. Goodwin RD. Association between physical activity and mental disorders among adults in the United States. Prev Med 2003;36:698-703. 
34. Baumeister H, Hutter N, Bengel J. Psychological and pharmacological interventions for depression in patients with coronary artery disease. Cochrane Database Syst Rev 2011;9:CD008012.

35. Pizzi C, Rutjes AW, Costa GM, Fontana F, Mezzetti A, Manzoli L. Meta-analysis of selective serotonin reuptake inhibitors in patients with depression and coronary heart disease. Am J Cardiol 2011;107:972-9.

36. Kuhl EA, Fauerbach JA, Bush DE, Ziegelstein RC. Relation of anxiety and adherence to risk-reducing recommendations following myocardial infarction. Am J Cardiol 2009;103:1629-34.

$* * * * * * * * * * * * * * * * * * * * * * * * * * * * * * * * * * * *$

Acknowledgements - Nil

Conflict of Interest - Nil

Funding - Nil 